\title{
Elevated transcription of transposable elements is accompanied by het-siRNA- driven de novo DNA methylation in grapevine embryogenic callus
}

Darrell Lizamore ${ }^{1 *}$, Ross Bicknell ${ }^{2}$ and Chris Winefield ${ }^{3^{*}}$

\begin{abstract}
Background: Somatic variation is a valuable source of trait diversity in clonally propagated crops. In grapevine, which has been clonally propagated worldwide for centuries, important phenotypes such as white berry colour are the result of genetic changes caused by transposable elements. Additionally, epiallele formation may play a role in determining geo-specific ('terroir') differences in grapes and thus ultimately in wine. This genomic plasticity might be co-opted for crop improvement via somatic embryogenesis, but that depends on a species-specific understanding of the epigenetic regulation of transposable element (TE) expression and silencing in these cultures. For this reason, we used whole-genome bisulphite sequencing, mRNA sequencing and small RNA sequencing to study the epigenetic status and expression of TEs in embryogenic callus, in comparison with leaf tissue.

Results: We found that compared with leaf tissue, grapevine embryogenic callus cultures accumulate relatively high genome-wide $\mathrm{CHH}$ methylation, particularly across heterochromatic regions. This de novo methylation is associated with an abundance of transcripts from highly replicated TE families, as well as corresponding $24 \mathrm{nt}$ heterochromatic siRNAs. Methylation in the TE-specific CHG context was relatively low over TEs located within genes, and the expression of TE loci within genes was highly correlated with the expression of those genes.

Conclusions: This multi-'omics analysis of grapevine embryogenic callus in comparison with leaf tissues reveals a high level of genome-wide transcription of TEs accompanied by RNA-dependent DNA methylation of these sequences in trans. This provides insight into the genomic conditions underlying somaclonal variation and epiallele formation in plants regenerated from embryogenic cultures, which is an important consideration when using these tissues for plant propagation and genetic improvement.
\end{abstract}

Keywords: Epigenetics, Transposable element, Embryogenic callus, Het-siRNA, Grapevine, Somaclonal variation, DNA methylation.

\footnotetext{
* Correspondence: Darrell.Lizamore@bri.co.nz; Chris.Winefield@Lincoln.ac.nz

'Bragato Research Institute, Blenheim, Marlborough, New Zealand

${ }^{3}$ Department Wine, Food and Molecular Biosciences, Lincoln University, Canterbury, New Zealand

Full list of author information is available at the end of the article
}

(C) The Author(s). 2021 Open Access This article is licensed under a Creative Commons Attribution 4.0 International License, which permits use, sharing, adaptation, distribution and reproduction in any medium or format, as long as you give appropriate credit to the original author(s) and the source, provide a link to the Creative Commons licence, and indicate if changes were made. The images or other third party material in this article are included in the article's Creative Commons licence, unless indicated otherwise in a credit line to the material. If material is not included in the article's Creative Commons licence and your intended use is not permitted by statutory regulation or exceeds the permitted use, you will need to obtain permission directly from the copyright holder. To view a copy of this licence, visit http://creativecommons.org/licenses/by/4.0/ The Creative Commons Public Domain Dedication waiver (http://creativecommons.org/publicdomain/zero/1.0/) applies to the data made available in this article, unless otherwise stated in a credit line to the data. 


\section{Background}

Preferential or obligate outcrossing enables plants to maintain genetic diversity in wild populations [1], and is common among perennial plants, which employ a range of physiological and genetic strategies to achieve selfincompatibility [2]. As a result, the genomes of these species are highly heterozygous. But efficient cultivation of these species requires homogenous populations in which preferential phenotypes are fixed. The centuriesold solution to domesticating highly heterozygous species is clonal propagation.

Modern grapevine (Vitis vinifera subsp. vinifera) is presumed to have been derived from the wild European grapevine (Vitis vinifera subsp. sylvestris) around 8,000 years ago [3]. The long history of grapevine cultivation provides an unique example of vegetative propagation. Pliny the Elder described the clonal cultivation of grapevine nearly two millennia ago in Natural History (AD 77). Today, the names of many centuries-old varieties such a as 'Pinot noir' and 'Chardonnay' are well known to wine consumers [4]. They provide signals of quality by which wine is marketed, but can also represent an obstacle to grapevine breeding efforts, which produce new and unknown varieties [5, 6].

However, plant genomes are not invariable in the absence of sexual reproduction. Occasionally, mutations in somatic tissues become fixed when material is collected from chimeric plants for propagation. Where mutations produce visible phenotypes, termed 'bud sports', they can provide genetic variation from which to select valuable traits, thus providing an alternative route for crop improvement. Seedless varieties such as 'Sultana' and white-skinned varieties such as 'Pinot blanc' are examples of economically important traits that have become established through the artificial selection and clonal propagation of somatic mutations that would be under negative selective pressure in the wild [7].

Sequence comparisons show that most variation among grapevine clones is due to the activity of transposable elements (TEs) [8]. These repeat sequences are ubiquitous in eukaryote genomes and comprise the majority of the nuclear DNA in many plant species. They are broadly categorised into Class I elements (retrotransposons), which replicate via an RNA intermediate, and Class II elements (DNA transposons), which mobilise via the excision and re-insertion of a section of doublestranded DNA within the host genome [9]. Because of these differences in mobility, retrotransposons tend to increase in abundance within the host genome and typically outnumber DNA transposons. Analyses of the grapevine reference genome show that TEs account for approximately half of the nuclear DNA including representatives of eight out of the nine recognised TE superfamilies (the exception being Tc1-Mariner) [10, 11].
Because of their potential mutagenicity, host species have evolved ways to repress TE activity by transcriptional gene silencing (TGS) and post-transcriptional gene silencing (PTGS) [12]. The large complement of silenced TEs in plant genomes acts as a source of sequence homology by which active TEs can be recognised and targeted for TGS, in a process known as RNAdirected DNA methylation (RdDM). In the canonical RdDM pathway, the plant-specific RNA polymerase RNA Pol IV transcribes heterochromatic TEs associated with $\mathrm{H} 3$ histones methylated at lysine 9 (H3K9me). The transcripts are converted to double-stranded RNA by RNA-DEPENDENT RNA POLYMERASE 2 (RDR2) and processed into 24-nt small interfering RNAs (siRNAs) by DICER-LIKE 3 (DCL3). These so-called heterochromatic siRNAs (het-siRNAs) direct ARGONAUTE 4 \& 6 (AGO4 \& AGO6) to nascent TE transcripts generated by RNA Pol V in a homology-dependent way, where they trigger the methylation of cytosine bases and ultimately H3K9me. In cases where TEs escape TGS (either through the introduction of new TEs for which no homology exists in the genome, or failure of the RdDM pathway), the host cell needs to both initiate PTGS to remove TE transcripts, and establish de novo methylation of the TE locus. The PTGS and non-canonical RdDM pathways depend on 21-22 nt siRNAs from a variety of sources including Pol II TE transcripts converted to dsRNA by RDR6 and subsequently processed into 21-22 nt siRNAs by DCL2 \& DCL4. These secondary siRNAs target TE transcripts for degradation via RNA interference (RNAi) and guide homologydependent TE methylation in a non-canonical RdDM pathway known as RDR6-RdDM $[12,13]$.

Without maintenance, cytosine methylation that represses TE transcription would be passively lost at each replication cycle. To prevent this, cytosines in symmetrical CG and CHG motifs (where $\mathrm{H}$ is $\mathrm{C}, \mathrm{A}$ or $\mathrm{T}$ ) are actively copied to the newly synthesised DNA strand by METHYLTRANSFERASE 1 (MET1) \& CHROMOMETHYLASE 3 (CMT3) respectively. Cytosine methylation in the asymmetrical $\mathrm{CHH}$ context cannot be copied between strands. Instead it is applied at each cellular generation by CMT2, which methylates heterochromatic DNA, or through RdDM via DRM2 [14].

Mobilisation of TEs can alter genes and their expression in subtle and complex ways. Besides disrupting open reading frames and protein recognition sequences, transposition events can cause gene duplication, alternative splicing and create new regulatory networks [15, 16]. Host efforts to epigenetically repress TE expression can affect nearby DNA, and indeed have been co-opted for gene regulation in some cases [17, 18]. Similarly, many TEs have accumulated stress-response regulatory elements over time. As this upregulates their activity in 
response to environmental stress, such TEs may even provide the host with a mechanism for increasing variation at times when it is most needed [19]. Therefore, besides their role as genomic 'parasites', domesticated TEs occasionally also provide a useful mechanism for adaptation that can be co-opted for crop improvement $[20,21]$.

Through judicious application of phytohormone regimes during tissue culture, certain somatic plant tissues can be converted to totipotent embryogenic callus (EC). The de-differentiated cells of EC can then be either propagated or allowed to differentiate into bipolar embryos. Somatic embryogenesis has been used to study the biological process of embryogenesis and to clonally propagate certain crops, such as forestry species [22]. In many species, including grape, embryogenic callus is also a target tissue research involving gene discovery, transgenic techniques and gene editing using CRISPR/Casbased approaches, as it minimises chimerism in regenerated plants [23-25]. But tissue culture is known to exert a mutagenic effect on plant cell lineages, leading to genomic changes known collectively as somaclonal variation. Certain plant TEs are activated by cell culture, and their mutagenic potential may be exacerbated by the abiotic stresses and phytohormones that are part of the process [26, 27]. Plants, including grapevine, regenerated from EC have also been seen to harbour epigenetic DNA changes [28-31]. Epiallele variation of this type may be particularly relevant to vegetatively propagated crops, though epialleles have also been seen to persist for multiple seedling generations [32]. In fact, stable epigenetic variation has been used to differentiate grapevine clones [33] and may be a key factor underlying the 'terroir' differences observed between identical clones in different winegrowing regions $[34,35]$.

Somaclonal variation has certain advantages for perennial crop improvement. Unlike hybrid varieties, novel clones can be deployed by the industry with no effect on varietal identity or the need for multi-generation backcrossing. But for somaclonal mutation to be used efficiently, a species-specific understanding of the types and rates of genetic and epigenetic change induced by somatic embryogenesis is needed [36]. We aimed to study the mechanisms of genetic and epigenic somaclonal variation in EC by comparing these cultures with leaf tissue, which is terminally differentiated. To do this we used whole-genome bisulphite sequencing to map the methylomes of EC and leaf tissue at single base-pair resolution. From these we analysed how the patterns of genomewide methylation in these tissues differ across genes and TEs, and in particular at loci where these two feature types overlap. To understand how the expression of TEs and their genic context is related to their epigenetic state, we then compared the differential expression of
TEs and the genes with which they are co-located. Finally, we analysed the small RNA complement of each tissue, since these molecules guide homology-dependent TE silencing. This multi-'omics approach provides a snapshot of the activity and impact of TE expression and silencing in EC, contrasted with leaf tissue, which is frequently used to compare methylation between and within plant species.

These results, and future work to understand the impact of these events on regenerated plants, will have practical implications for the use of EC for somaclonal crop improvement. Furthermore, observations of the genomic effects of this TE activity and host response in totipotent cells in vitro may also help clarify the role of developmental relaxation of TE silencing (DRTS) in whole plants.

\section{Results}

\section{TE methylation in Embryogenic callus}

To compare the genome-wide DNA methylation profiles of EC with those of leaf tissue, whole-genome bisulphite sequencing was performed for both tissue types. Bisulphite conversion rates were 99.59 and $99.72 \%$ for leaf and EC libraries respectively, and global read coverage after mapping was 36-fold for the leaf library and 32fold for the EC library (Suppl. Table S1).

Cytosine methylation in EC was found to be higher than in leaf for each cytosine context (Fig. 1A). This is consistent with previous reports that have shown genome-wide dispersed hypermethylation in callus cultures of Arabidopsis, maize and rice [37-39]. Most notable was the relatively high proportion $(21.8 \%)$ of $\mathrm{CHH}$ methylation in EC, which was very low $(1.7 \%)$ in the leaf tissue samples. To further study the genomic context of DNA hypermethylation in EC, we analysed methylation across TEs and genes separately. This required that we first annotate repeat loci in the reference genome based on sequence similarity with published Vitis vinifera repeat sequences, which yielded 222,411 annotations (Suppl. Fig. S1; the annotation track is available for download at DOI: https://doi.org/10.6084/m9.figshare. 14709816).

In both tissue types, genes were more highly methylated than adjacent DNA in the CG context but less methylated than adjacent DNA in the CHG context (Fig. 1B). In contrast, regardless of tissue type or cytosine context, methylation across TEs was found to be higher than that of adjacent DNA. For CG and CHG contexts, methylation in EC was higher than that of leaf tissue across annotated TEs, but not across genes, indicating that the overall differences in global methylation percentages were associated with hypermethylation of TEs in the callus (Fig. 1B). The exception to this trend was $\mathrm{CHH}$ methylation. Although $\mathrm{CHH}$ methylation in 


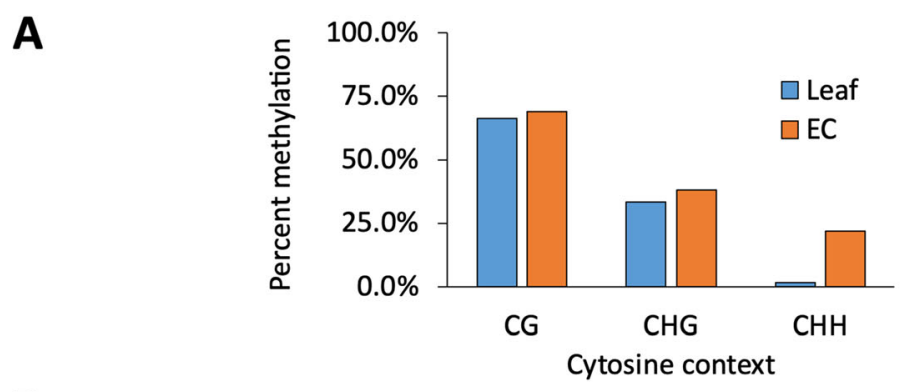

B

CG

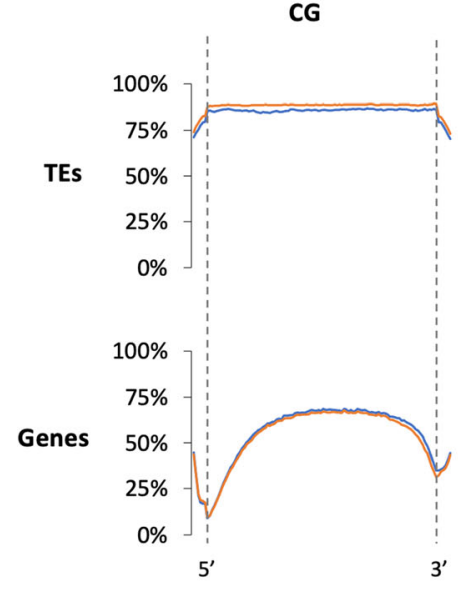

CHG

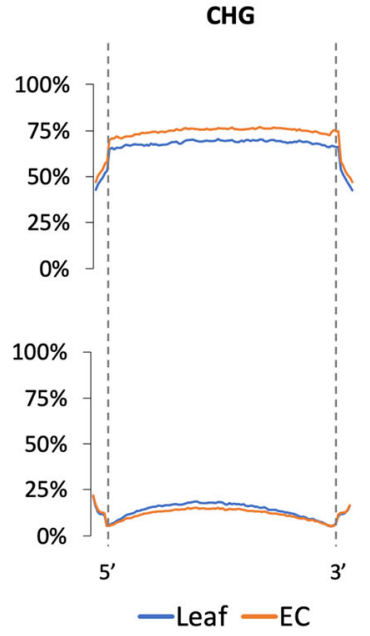

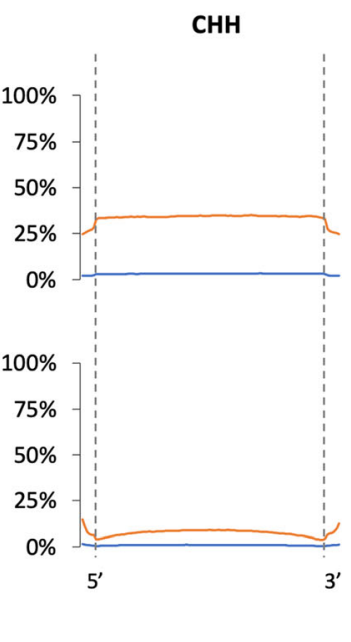

Fig. 1 Cytosine methylation differences between leaf and EC. A: Global methylation by cytosine context for both tissue types. B: Profiles of DNA methylation across TE and gene feature types by cytosine context, with adjacent $1 \mathrm{~kb}$ flanking regions shown. Dashed lines indicate feature boundaries

EC was particularly high across TEs, $\mathrm{CHH}$ methylation across genes was also higher in EC than in leaves. A potential explanation for this is the presence of TEs containing hypermethylated $\mathrm{CHH}$ sites situated within genes. To determine whether this was indeed the case, we further analysed TEs that are co-located with genes (defined as those that overlapped gene annotations by at least $1 \mathrm{bp}$ ), which we termed 'genic TEs', and 'intergenic TEs' (those that do not overlap gene annotations) separately. By overlaying the TE and gene feature annotation sets, we found that 49,257 (21.9\%) of TEs overlapped annotated genes. Of the 31,845 gene features in the $\mathrm{V}$ 2.1 annotation set, 11,311 (35.6\%) were co-located with TEs. This indicates that in grapevine many TEs are dispersed through protein-coding regions of the genome.

Methylation in the CG context was found to be constitutively high across both genic TEs and intergenic TEs in leaf tissue and EC (Fig. 2A). However, while intergenic TEs generally had high GHC methylation in both tissue types, genic TEs showed a bimodal distribution, particularly in leaf tissue where TEs co-locating with genes were either highly $\mathrm{CHG}$ methylated or relatively unmethylated in this context. Interestingly, many genic
TEs that had high CHG methylation in leaf tissue showed reduced methylation in EC. CHG methylation acts as a functional signal for TE silencing in plants, and loss of this signal can permit TE expression to disrupt nearby genes. This has been seen in the case of the MANTLED locus in oil palm, which is the site of a TE insertion related to the Karma rice retrotransposon in the intron of the homeotic gene DEFICIENS. Loss of CHG methylation at this locus leads to alternative splicing, resulting in a prematurely terminated gene transcript [31]. While a proportion of genic TEs demonstrated CHG hypomethylation in EC relative to leaves, intergenic TEs tended to show slightly higher CHG methylation in EC than in leaf tissue.

Asymmetric $\mathrm{CHH}$ methylation, which is indicative of active de novo methylation, was largely absent in leaf tissue. In contrast, TEs in EC displayed significant $\mathrm{CHH}$ methylation, particularly across intergenic TEs (Fig. 2A). To better visualise the degree to which TEs varied in methylation between the two tissues, density plots were generated for all TEs with at least $20 \%$ methylation in one tissue (Fig. 2B). While CG methylation of TEs appeared to be independent of co-located genes, intergenic 


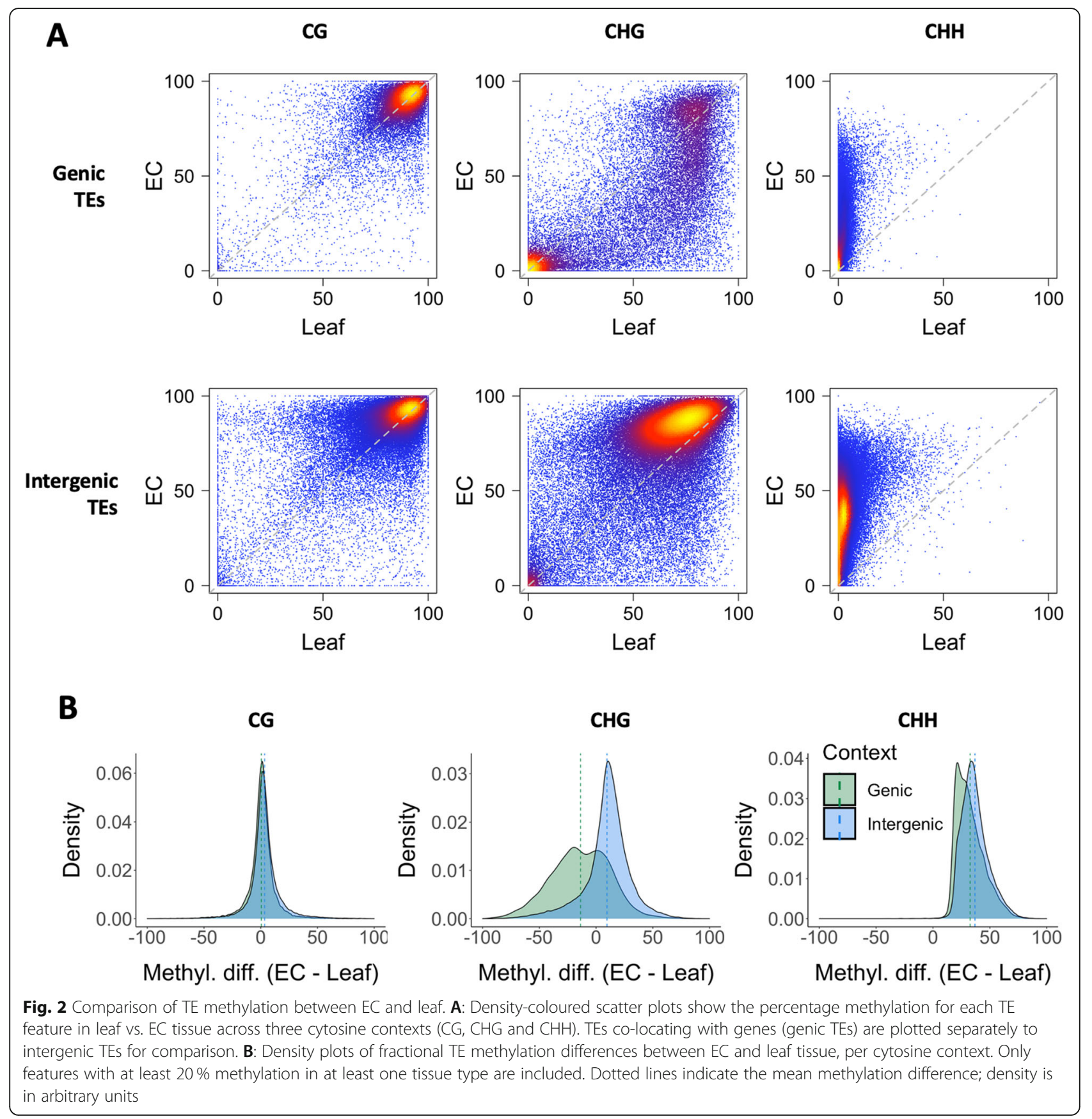

TEs had higher CHG methylation in EC, whereas a large proportion of genic TEs showed lower CHG methylation. As described above, $\mathrm{CHH}$ methylation of TEs was higher in EC, with the effect greatest for intergenic TEs.

\section{High TE expression in EC}

Since methylation in plants is functionally important for silencing TEs, we wanted to see if the observed genomewide changes to TE methylation were associated with a corresponding difference in TE expression. To do this, we performed sequencing on triplicate RNA libraries from each tissue type. The two genes with the highest read counts in leaf tissue were VIT_213s0019g0263 (mean 63,259 reads per million mapped) and VIT 207 s0031g03000 (mean 8,480 reads per million mapped). Closer inspection revealed sequence homology with chloroplast genes $p s b A$ (photosystem II D1 protein) and $r b c L$ (RuBISCO large subunit). This is likely due to overassembly of the reference genome, as has been reported elsewhere [40]. Read counts for these two genes were 
removed from count tables prior to normalisation, in order to compare the expression of nuclear genes between the two tissues.

We found that the proportion of reads mapping to TEs was significantly higher $(p<0.001)$ in RNA libraries of EC $(9,278 \pm 508$ reads per million), compared with those from leaf $(3,820 \pm 735$ reads per million). Differential expression analysis identified 14,229 differentially expressed (DE) genes, with 8,210 more highly expressed in leaf and 6,019 more highly expressed in EC (Fig. 3A; Suppl. Table S2). Of the 105 differentially expressed TE families identified, 85 were more highly expressed in EC (Fig. 3B C; Suppl. Table S3). Each of the transposon superfamilies, with the exception of LINEs, included TE families more highly expressed in EC compared with leaf tissue (Fig. 3C \& D). Although differential expression of LINE elements did not cross the threshold for significance, all LINE families had higher mean expression among EC replicates compared with leaf replicates (Suppl. Table S3).

Genes more highly expressed in EC were summarised into 12 ontological categories by enrichment analysis. These categories showed an overall upregulation of genes associated with the functions of DNA replication and cell division (Fig. 3E). Grouped within the second most enriched category, 'DNA Methylation' (GO: 0006306), were 8 other significantly enriched GO terms associated with epigenetic activity (Fig. 3E, inset) These ontologies cover the breadth of small-RNA driven chromatin modification and DNA methylation described above, including RdDM. Genes more highly expressed in leaf grouped into 36 ontological categories, including terpenoid production, defence response and photosynthesis (Suppl. Fig. S2). To further determine how the observed hypermethylation of DNA in EC relative to leaf might relate to gene expression, we compared the expression of DNA methyltransferase genes previously described in grapevine [41]. Of these, DDM1, CMT1, CMT2 and MET1 were found to be more highly expressed in EC, while DRM2 and CMT3 showed no significant difference (Fig. 3F).

Since TEs exist as multiple copies in individual genomes, short sequencing reads frequently map to multiple genic loci. In order to quantify $\mathrm{TE}$ transcript abundance, bioinformatic tools such as TEtranscripts count ambiguously mapped reads to compare the expression of TEs at the family level, rather than individual insertions. Given the significant differences between the methylation profiles of genic and intergenic TEs, we wanted to know whether there was any relationship between the expression of specific TE loci and the transcription of co-located genes. To determine this, DE analysis was subsequently performed using only uniquely mapping reads. Of the 2,278 discrete genic TE loci (TE loci overlapping annotated genes) that passed the significance threshold for differential expression using this approach, 1,576 (69\%) were co-located with genes also passing the threshold for significant DE. Expression of TEs was closely correlated with that of co-located genes, providing evidence that in general the transcription levels of individual TEs are linked to the level of transcription of the genes within which they are located (Fig. 3G).

\section{Heterochromatic siRNAs accumulate in EC}

Sequence-specific recognition of TEs for RdDM and PTGS depends on the presence of small RNAs to guide protein complexes to their targets. Our comparison of the DNA methylation profile and transcriptome of grapevine EC with leaf tissue demonstrated a marked difference with regards to TE silencing across the genome. To interrogate the dynamics of the host cell's TE repression in these tissues we decided to sequence the sRNA complement present.

After adapter trimming and quality and fragment length filtering, 85 and $69 \%$ of the reads remained for the leaf and EC small sequencing libraries respectively (Suppl. Table S4). Micro RNAs (miRNAs) accounted for $2,040,584$ reads in the leaf library (25.9\% of total reads), but only 27,896 reads $(0.4 \%)$ of the EC library. Of the miRNA expressed in leaf tissue, $33.3 \%$ were from a single miRNA family, miR166, as previously reported [42]. To compare the abundance of siRNAs apart from this difference in miRNA expression, siRNA were normalised to the size of read libraries after miRNA removal.

After removing miRNAs, 21 nt siRNAs, which are associated with both non-canonical RdDM (TGS) and RNAi (PTGS), were found to be higher in leaf tissue (Fig. 4A). In contrast, 24 nt het-siRNAs, which initiate canonical RdDM, were higher in EC. The mapped siRNA were clustered by ShortStack into a total of 89,597 DicerCall clusters in leaf and 227,847 DicerCall clusters in EC. To determine the location bias of the clusters, GAT was used to asses enrichment across three feature types: genes, promotors (regions $2 \mathrm{~kb}$ upstream of genes) and TEs. In leaf tissue, 21 nt siRNA clusters were found to be enriched in genes and depleted in TEs, whereas 23 and 24 nt siRNA clusters were depleted in genes and enriched in promoters and TEs (Fig. 4B). EC showed depletion of siRNA clusters of all sizes except 21 nt in genes and their promoters but an enrichment for clusters of all siRNA sizes in TEs, with $24 \mathrm{nt}$ siRNAs most enriched.

For 21-22 nt siRNAs, which include secondary and phased small RNAs, the relatively higher abundance in leaf was due to sequences associated with gene exons (Fig. 4C). However, the increase in $24 \mathrm{nt}$ siRNAs in EC was particularly associated with TEs, mostly in 
A

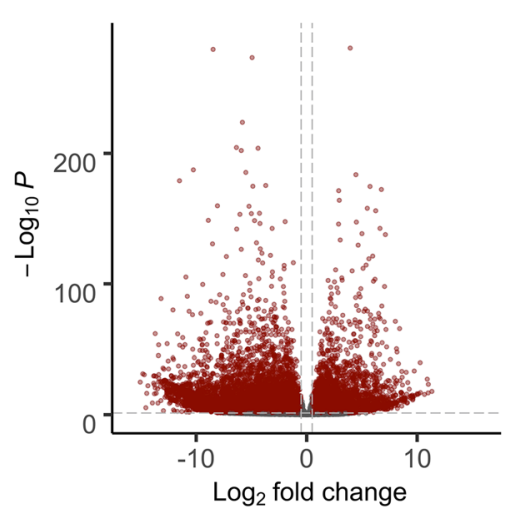

C

\begin{tabular}{|lccc|}
\hline Superfamily & Leaf & EC & $\begin{array}{c}\text { Non- } \\
\text { significant }\end{array}$ \\
Class I: & & & \\
Copia & 11 & 31 & 58 \\
Gypsy & 4 & 14 & 18 \\
LINE & 0 & 0 & 10 \\
Class II: & & & \\
CACTA & 2 & 5 & 8 \\
hAT & 0 & 10 & 5 \\
Harbinger & 0 & 7 & 4 \\
Helitron & 0 & 1 & 0 \\
MULE & 3 & 17 & 17 \\
\hline Total & 20 & 85 & 120 \\
\hline
\end{tabular}

B

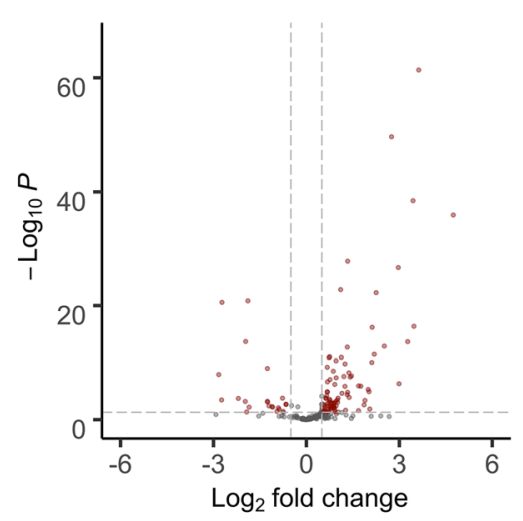

D

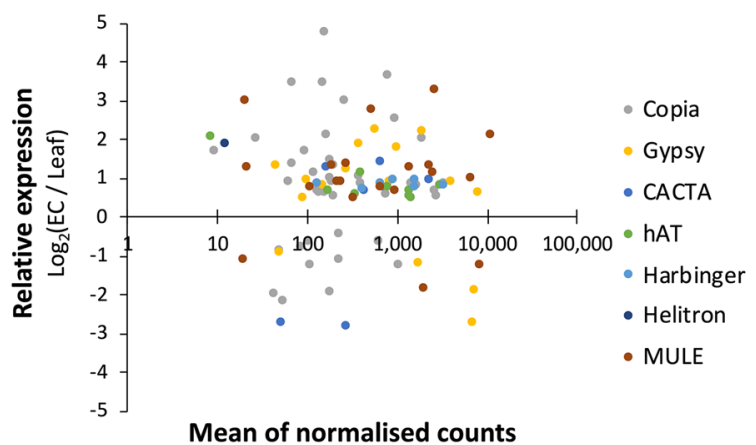

\section{E}
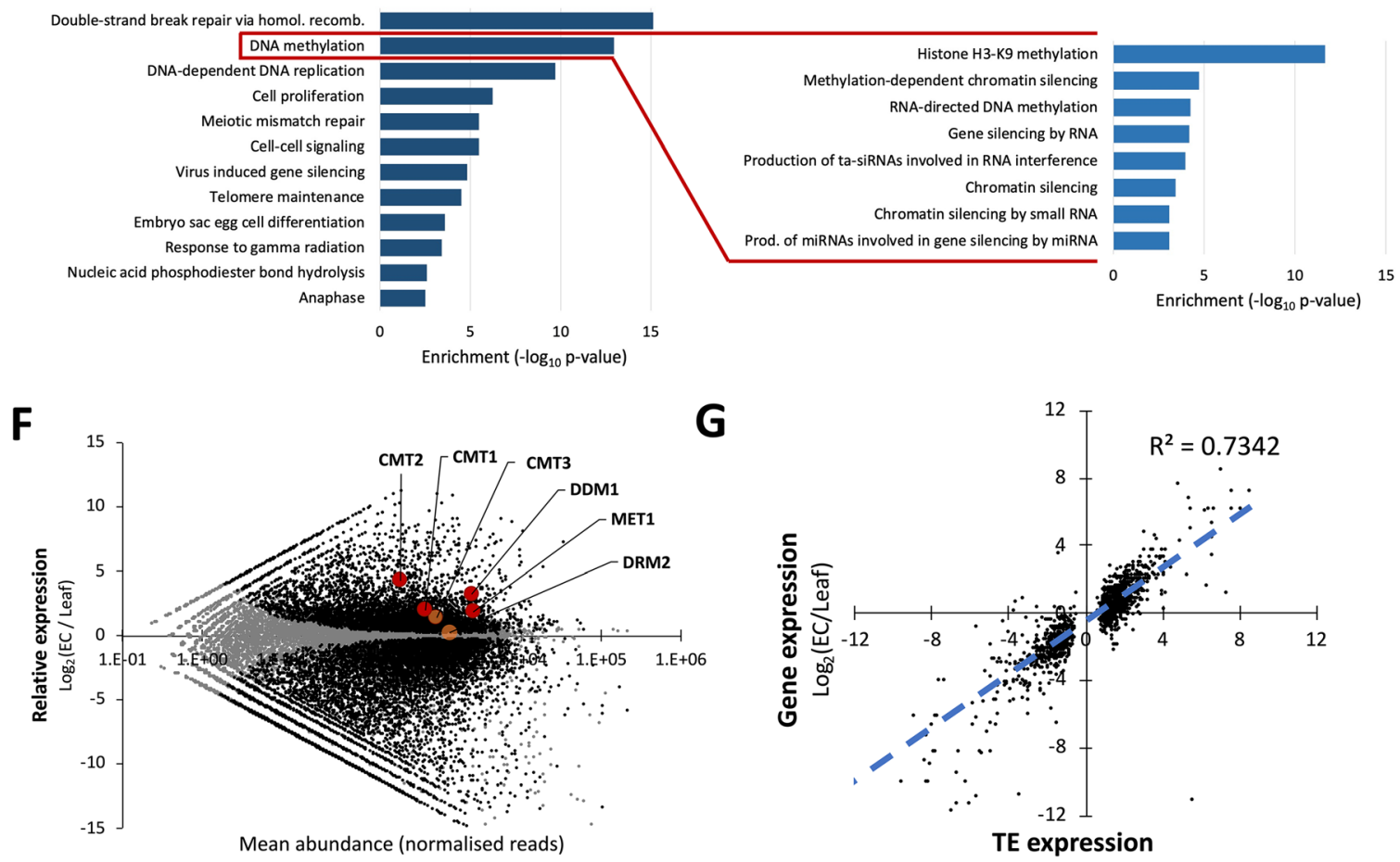

G

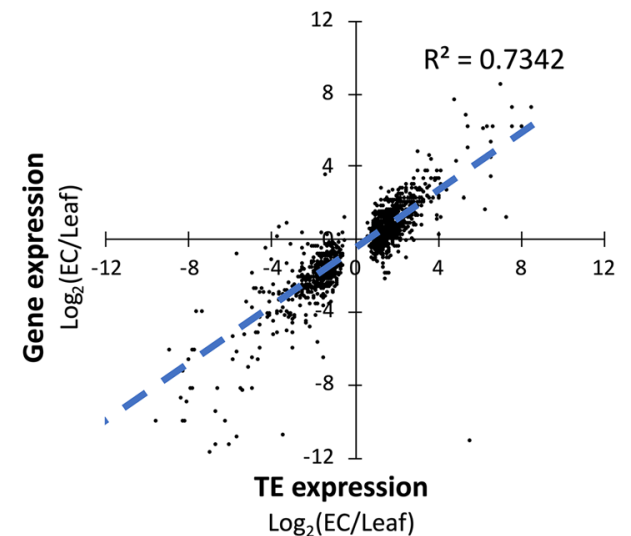

Fig. 3 (See legend on next page.) 
(See figure on previous page.)

Fig. 3 Transcription of TEs in grapevine EC, compared with leaf. Volcano plot of gene differential expression analysis for $\mathbf{A}$ : Genes and $\mathbf{B}$ : TEs. Features significantly DE $(p<0.05)$ with $\mid$ Log2 Fold Change $(E C / L e a f) \mid>2$ are highlighted in red. C: Counts of TE families with relatively higher expression levels in each tissue type. D: m-a plot of TE families differing significantly in expression between leaf \& EC tissue, coloured by TE superfamily. E: GO terms enriched among DE genes highly expressed in EC relative to leaf, grouped by similarity. Enriched terms grouping under "DNA methylation" are shown in the expansion to the right. F: $\mathrm{m}$-a plot of gene expression (expression in EC / expression in leaf). Genes not passing the significance threshold (adjusted $p<0.05$ ) are shown in grey. DNA methyltransferase genes are highlighted in red where significantly DE and in orange where no significant difference is observed. G: Relative expression of DE TEs between tissue types, compared with the relative expression of co-located DE genes

intergenic space. As in the case of the mRNA transcript libraries, the relative abundance of $24 \mathrm{nt}$ sRNAs was not limited to individual TE superfamilies. Rather, the increase in het-siRNAs was associated with Gypsy, Copia, LINE, CACTA \& MULE superfamilies, with those mapping to Gypsy elements accounting for $56.2 \%$ of the difference in 24 nt siRNAs between the two tissue types (Fig. 4D).

Integrating all three datasets showed that in EC the increased TE expression, siRNA abundance and $\mathrm{CHH}$ methylation relative to leaf are associated with the same TE families (Fig. 5). Furthermore, the TE families that

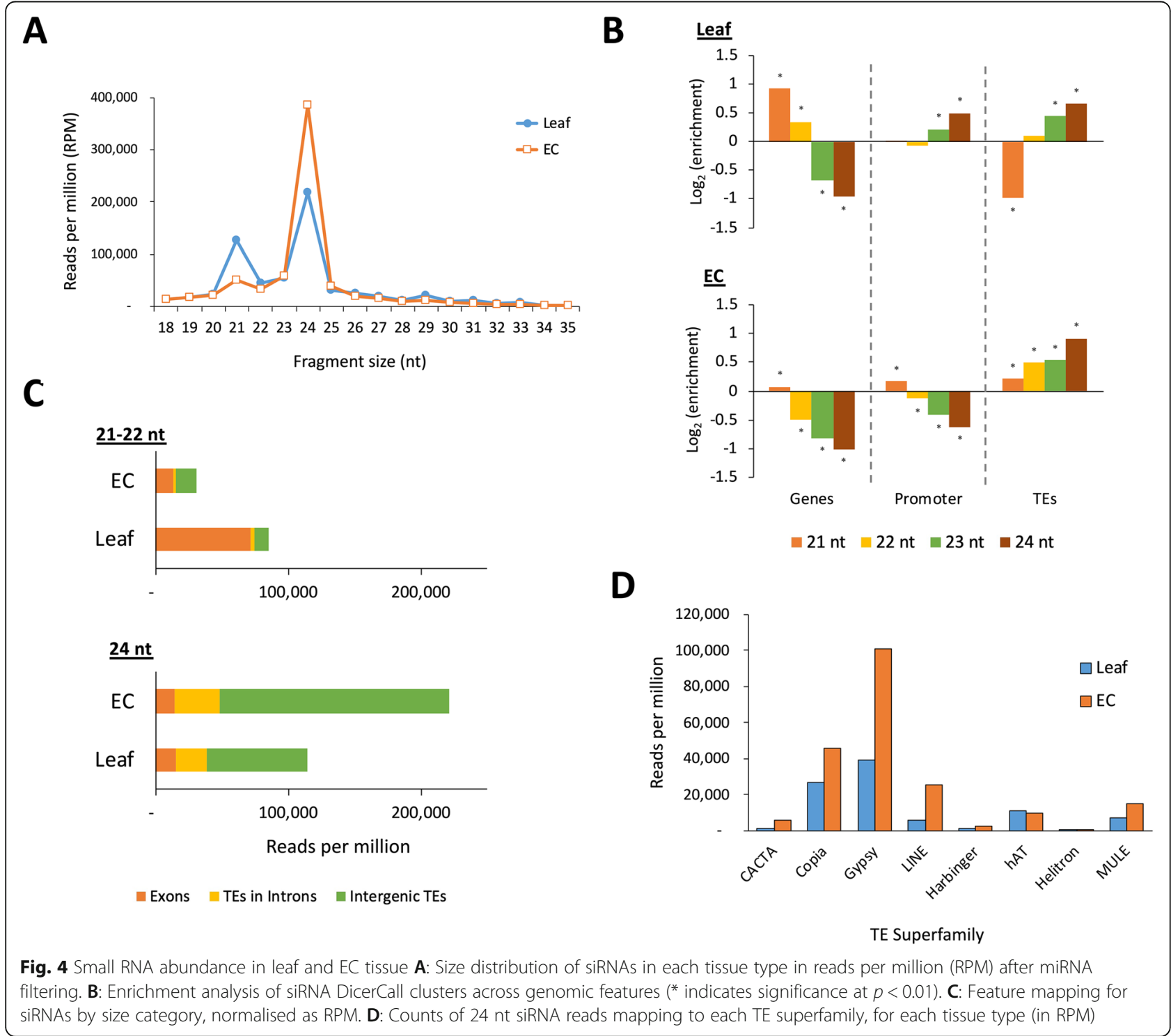




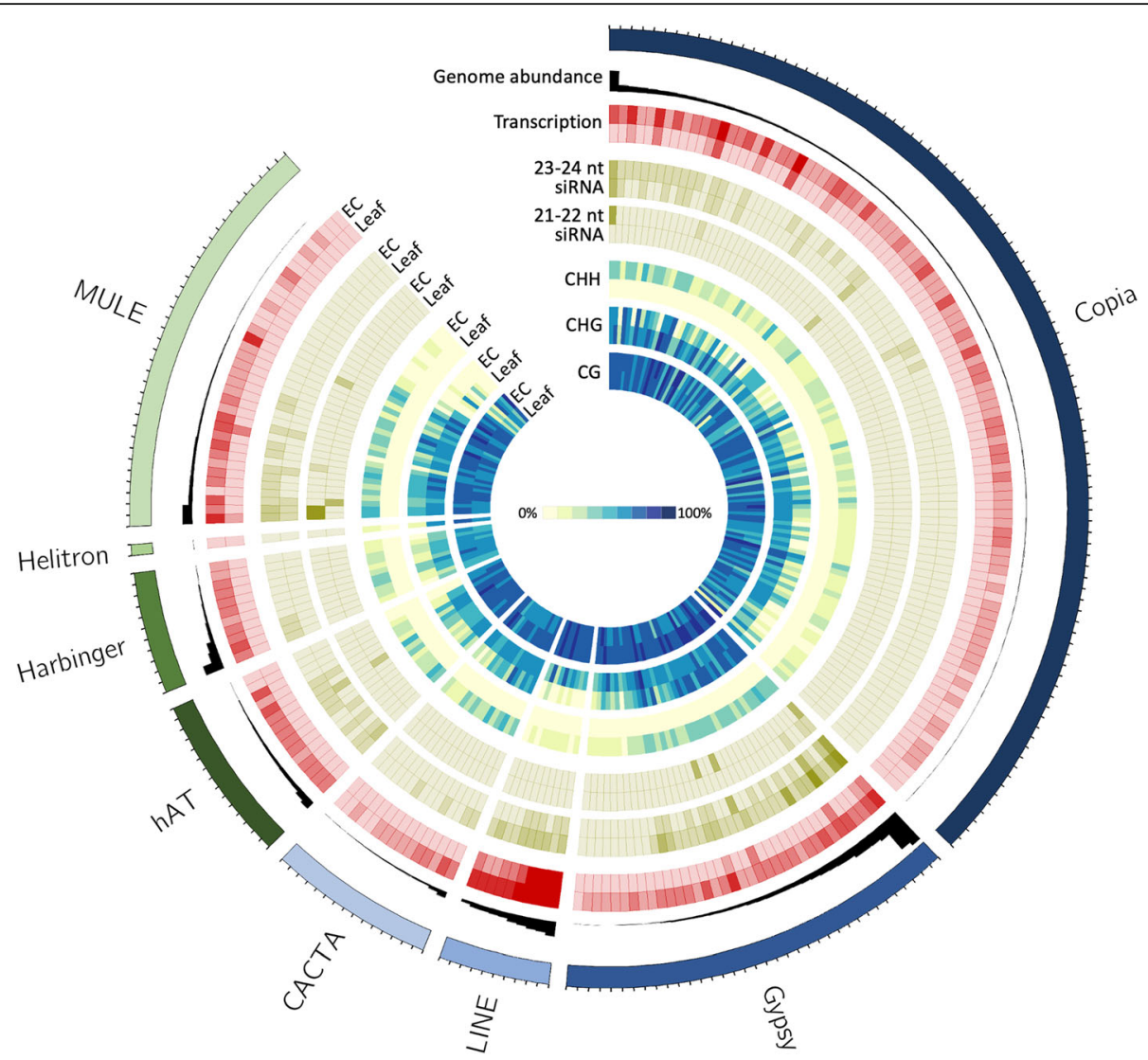

Fig. 5 Transcription, small RNA abundance and methylation in embryogenic callus and leaf by TE family. Mean data is reported per TE family, which are represented by outer tick marks, grouped by superfamily and sorted in order of repeat abundance in the Vitis vinifera genome. Tracks, starting from the outside are: Vitis vinifera TE families, grouped by superfamily (ideograms); number of copies per genome (black histogram); normalised transcript abundance (red heat maps); normalised 21-22 nt siRNA abundance (outer brown heat maps); normalised 21-22 nt siRNA abundance (inner brown heat maps); mean CHH methylation, mean CHG methylation and mean CG methylation (yellow to blue heat maps, see scale in the centre)

were more abundant in the grapevine genome appeared to be those for which the expression and de novo silencing responses were highest.

\section{Discussion}

Tissue culture, including somatic embryogenesis, has long been recognised to have a mutagenic effect on plant genomes that is mediated by TE activity [43-46]. This fact can frustrate efforts to recover specific genotypes following tissue culture [47, 48]. Tang and colleagues, for example, found that somaclonal mutations were far more abundant than off-target mutations in genomeedited rice lines [49]. But TE-derived somaclonal variation has the potential to provide valuable diversity [50]. In rice the Copia-type retrotransposon Tos17, which is stimulated by prolonged tissue culture and has been shown to preferentially insert into gene-rich regions, has been used to produce a population of over 47,000 insertion mutants [51]. Similarly, tissue culture induced transposition of LORE1 has been used for saturation mutagenesis in Lotus japonicus [52]. This diversity is particularly attractive as a source material from which to make selections when other crop improvement techniques are limited. In the case of grapevine, for example, the fact that varietal identity is a premium indicator of wine quality means that support for breeding approaches is limited for commercial reasons.

Since Barbara McClintock's discovery of "dissociation" (Ds) elements in maize [53], most studies investigating the role of transposition in somatic mutagenesis have focussed on individual TE families. This is because most active transposons were identified and characterised following the observation of an atypical phenotype. However, the advent of massively-parallel sequencing techniques, together with publicly available reference genome assemblies, enable the expression and silencing of the entire mobilome (mobile portion of the genome) to be studied simultaneously. To do this, we used three sequencing approaches to characterise the methylation, transcription and small RNA-targeting of TEs in EC 
cultures. We compared these with leaf tissue, a terminally differentiated tissue frequently used as a reference for studies comparing the methylation of different plant tissues and species [39, 54-57].

The genome-wide methylation levels observed in leaf samples were comparable to those that have been previously reported for Vitis vinifera [55]. The most distinctive difference between the epigenetic state of EC and leaf tissue was the relative abundance of $\mathrm{CHH}$ methylation in EC cells, which was almost absent in leave tissue. Increased $\mathrm{CHH}$ methylation has been previously reported in totipotent cell cultures of rice (Oryza sativa) [37] and sugar beet (Beta vulgaris) [54], Arabidopsis embryos [58] and soybean (Glycine max) seeds [57], although at lower levels than reported here $(17 \%, 14 \%, 5$ and $9 \%$ respectively). Elevation in $\mathrm{CHH}$ methylation appears to accompany dedifferentiation in plant cells, though the high levels are not typically retained in plants regenerated from these tissues [58].

In plants, asymmetric $\mathrm{CHH}$ methylation is catalysed by heterochromatin-targeting CMT2 and by the $24 \mathrm{nt}$ siRNA-guided Pol IV-RdDM pathway. In this study we found that CMT2 was more highly expressed in EC than leaf and that TEs in intergenic regions carried higher $\mathrm{CHH}$ methylation than those within genes (Fig. 2A). The relatively long $24 \mathrm{nt}$ siRNAs were also found to be most abundant in EC (Fig. 4A), and these het-siRNA were enriched around TE features (Fig. 4B). These findings suggest both CMT2 and RdDM contribute to high $\mathrm{CHH}$ methylation in EC. While TE-specific CHG methylation was higher overall in EC than in leaf (Fig. $1 \mathrm{~A}$ ), no difference was seen in the expression of CMT3, which maintains CHG methylation following DNA replication. Interestingly, $\mathrm{TE}$ methylation in this context was dependent on the genomic context of the TEs. The majority of genic TEs had lower methylation in EC, but TEs in intergenic regions generally had higher CHG methylation (Fig. 2B). These results suggest that in EC cultures, the context of TEs with regard to genes is an important factor in determining whether they are silenced, which led us to analyse whether transcription of TEs depends on the transcription of co-located genes. Transcript libraries obtained from EC contained approximately twice the proportion of TE-mapping reads as those from leaf tissue. The relative abundance of TE transcripts was not due to high copy numbers of a few TE families. Rather, most TE families (85 out of 122) were significantly more highly expressed in EC. Analysing only unique-mapping transcript reads revealed that the majority of DE TEs were indeed co-located with DE genes.

By integrating the three data types, we suggest a descriptive model for the epigenetic state of TEs in grapevine EC. In these cultures, a diverse set of genic TEs are cotranscribed with the genes in which they lie. This appears to be associated with a reduction in CHG methylation across these elements. The increase in TE transcript abundance triggers a response in the form of het-siRNAs with sequence-specificity for the transcribed TEs. Consequently, the genome experiences a burst of $\mathrm{CHH}$ methylation via Pol IV-RdDM, leading intergenic TEs across the genome to be silenced in trans (Fig. 6). The genic context of TEs is key to understanding the finding that TEs in EC are both more methylated and more highly transcribed than in leaves. This finding seems at odds with the general belief that a primary function of epigenetic modifications (particularly CHG methylation, in the case of plants) is to silence TEs. However as discussed above, genic TEs in EC were relatively hypomethylated, but since there are far more intergenic TE copies which are hypermethylated, the total, aggregated methylation of TEs in EC was higher than in leaf. The reason that EC has reduced CHG methylation at genic TEs is not known, but a similar observation has previously reported in the case of the Bad Karma allele in oil palm [31]. The cause does not appear to be a decrease in CMT3 expression. It is notable the EC cells contained lower 21-22 nt siRNA abundance than leaf, and that the enrichment of 21 nt siRNA clusters across genes that was seen in leaf was almost absent in EC.

In plants, a general increase in TE expression is known to occur during DRTS, a tissue-specific phenomenon in which genome-wide loss of epigenetic silencing is accompanied by high rates of TE transcription and transposition [59]. DRTS has been observed in differentiated tissues adjacent to rapidly-multiplying pluripotent cells, including the pollen vegetative nucleus and endosperm in Arabidopsis and maturing leaves in maize [60-62]. It has been proposed that one function of DRTS may be to trigger the production of 21-22 nt small RNAs that are able to migrate into adjacent germline or meristematic tissues where they reinforce TE silencing via RNAi and RDR6-dependent $\operatorname{RdDM}[59,62]$. Despite the similar accumulation of TE transcripts from multiple families, the situation in grapevine EC differs in certain regards to canonical examples of DRTS. In Arabidopsis, heterochromatin loss is caused by reduced expression of the chromatin remodeller DDM1, allowing TE transcription [61]. In contrast, grapevine EC showed comparably high expression of DDM1 and DNA methyltransferases, while 21-22 nt siRNA levels were lower than in leaf tissue. Instead, 24 nt het-siRNAs, which target TEs for asymmetric $\mathrm{CHH}$ methylation, were most abundant. Rather than an example of DRTS, the case of grapevine EC may instead be analogous to an embryo lacking an adjacent endosperm. In this scenario, TEs co-located with expressed genes are transcribed and, without a source from which to import secondary siRNAs to guide RNAi, their transcripts accumulate. 
Leaf:

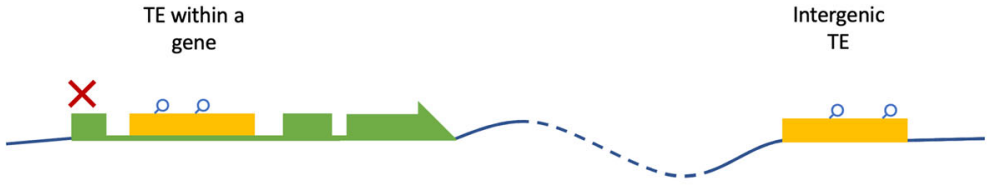

Embryogenic callus:

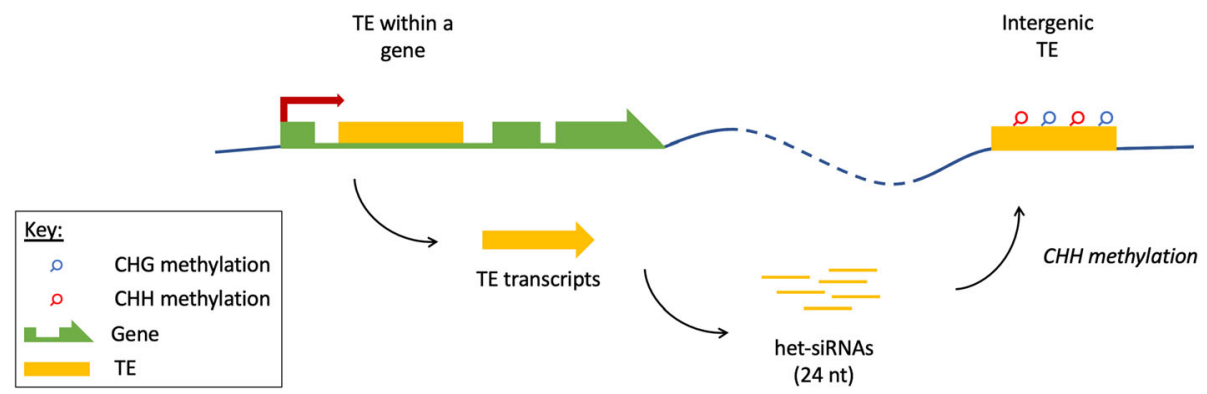

Fig. 6 A schematic overview of TE expression and silencing in leaf and EC. In leaf tissue, TE expression is generally low, with both genic and intergenic TEs methylated in CHG context. In EC, genic TEs have reduced CHG methylation and are transcribed with the genes in which they are co-located. This triggers RdDM, in which the TE transcripts are processed into $24 \mathrm{nt}$ het-siRNAs that guide trans silencing of repeat sequences across the genome

If EC is indeed analogous to naturally-occurring dedifferentiated tissues, it could provide a useful system in which to test current hypotheses about the evolutionary function of DRTS in plants. Most pertinent among these is the hypothesis that without secondary siRNAs imported from nearby tissue, TE transcripts in dedifferentiated cells would overwhelm the PTGS system and exceed the cells' ability to prevent transposition. Further work is needed to establish whether the high rates of transposition events observed in totipotent plant cell cultures can directly be attributed to a lack of imported secondary siRNAs. In this study, the transcription of TEs in EC was associated with a burst of de novo $\mathrm{CHH}$ methylation. Similarly, it remains to be seen whether this strand-specific methylation results in stable epigenetic changes in plants regenerated from these cultures, and if so, whether new epialleles affect the expression of nearby genes. In other species, increased $\mathrm{CHH}$ methylation is not typically seen in regenerated plants [58]. However, plants regenerated from tissue culture do frequently (though not consistently) demonstrate epigenetic variation, including in grapevine $[28,30,39]$.

\section{Conclusions}

In grapevine, transcription of almost all known TE superfamilies is higher in dedifferentiated EC cells of grapevine than in leaf tissue. This appears to be due to a the loss of CHG methylation across TEs within genes and the transcription of those genes. The accumulating TE transcripts are accompanied by a genome-wide epigenetic response involving an increase in het-siRNAs and de novo methylation of TE DNA in trans. It remains to be seen whether the burst of TE transcription and associated epigenetic response persists as somaclonal genetic or epigenetic variation in vines regenerated from these cultures.

These results add insight into the epigenetic regulation of transposition, particularly in embryogenic cell cultures. Understanding these factors is important given their use in studying embryogenesis and for crop improvement. Better control of transposition and epiallele formation will improve outcomes for producing new somaclonal variation, gene discovery and targeted gene editing, homogenous propagation of elite genotypes, and managing chimerism in plants regenerated from cell culture.

\section{Methods}

\section{TE annotation}

Transposable elements in the $V$. vinifera PN40024 12X reference genome [63] were annotated with RepeatMasker (v4.1.0; RRID:SCR_012954) [64]. Query sequences included $V$. vinifera repeat sequences from Repbase (RRID:SCR_021169) [65] supplemented with $V$. vinifera repeat sequences collected from published literature [11]. TE annotations were assigned a custom 
nomenclature that included class, superfamily, family and locus, for downstream analysis and sorting. Feature overlaps were identified by comparing annotated TEs with gene features from the $V$. vinifera V2.1 structural annotation [66], using the intersect function of the BEDtools toolkit (v2.29.2; RRID:SCR_006646) [67].

\section{Plant material}

Anther tissue was selected for EC initiation, due to the broad applicability of this technique across multiple grapevine varieties. Embryogenic cell cultures were established using the protocol of Perrin and colleagues [68] from anthers of immature inflorescences harvested from $V$. vinifera cv 'Chardonnay', grown at the Lincoln University research vineyard (Canterbury, New Zealand). Established cultures were grown on solid $\mathrm{C}_{1} \mathrm{P}$ media at $26 \pm 1{ }^{\circ} \mathrm{C}$ in the dark [69]. After three months, healthy white EC masses were transferred to fresh $\mathrm{C}_{1} \mathrm{P}$ media, leaving behind brown dark brown callus and anthers that showed no callus formation. Four months after initial callus formation, samples of these proliferating EC cultures from three Petri dishes were pooled per sample and harvested directly into liquid $\mathrm{N}_{2}$. For leaf tissue samples, young leaves $(<30 \mathrm{~mm}$ in diameter) were selected, which yield high quality DNA and RNA in grapevine. Samples were collected from the same vines described above (five leaves per sample) and harvested directly into liquid $\mathrm{N}_{2}$. Samples were stored at $-80^{\circ} \mathrm{C}$ until used for DNA and RNA purification.

\section{DNA methylation analysis}

Genomic DNA was extracted from $50 \mathrm{mg}$ aliquots of young leaf and embryogenic callus samples ground in liquid $\mathrm{N}_{2}$, using the NucleoMag ${ }^{\bullet}$ Plant DNA kit (Macherey-Nagel $\mathrm{GmbH}$ ) according to the manufacturer's instructions. Isolated DNA was stabilised using DNAstable (Biomātrica) and shipped to Macrogen (Seoul, Rep. of Korea) for library preparation and sequencing. Methylation-specific sequencing libraries were prepared using the TruSeq DNA Methylation kit (Illumina, Inc.) according to the manufacturer's specifications. Leaf and embryogenic callus libraries were multiplexed and sequenced on two lanes of a HiSeq 2000 flow cell using $100 \mathrm{bp}$ paired-end sequencing.

Read pairs were mapped to the 12X PN40024 grapevine reference genome using BS-Seeker2 (v2.1.8; RRID: SCR_020948) [70] with the parameters ' $\mathrm{X} 1000-\mathrm{m}$ 0.04'. Methylation calling and global methylation statistics were generated with the 'bam2cgmap' tool from the cgmaptools programme package [71]. Methylation across features and methylation per feature were calculated using the 'mfg' and 'mtr' functions from the same package, respectively. Only features which had a methylation effective coverage greater than 20 in both samples were included in the analysis of methylation across features. Data visualisation was performed in $\mathrm{R}$ ( $\mathrm{v} 4.0 .2$; RRID:SCR_001905). Bisulphite conversion efficiency was calculated by calculating methylation levels of all reads mapping to the non-methylated chloroplast genome (NCBI reference sequence: NC_007957.1).

\section{Transcriptome analysis}

RNA was purified from triplicate EC and leaf tissue samples using the Spectrum $^{\text {Tx }}$ Plant Total RNA kit (SigmaAldrich). Isolated RNA was quality checked using an Bioanalyzer 2100 with the RNA 6000 nano kit (Agilent Technologies, Inc.) according to manufacturer's instructions and $\mathrm{OD}_{260 / 280}$ ratios determined with a DS-11 spectrophotometer (DeNovix, Inc.). Quantification of RNA samples was done using a Qubit fluorometer (Thermo Fisher Scientific) and the samples were stabilised using RNAStable (Biomātrica, Inc.) prior to shipping to Macrogen for sequencing.

Library synthesis and sequencing was carried out by Macrogen (Seoul, Rep. of Korea). Briefly, libraries were prepared using a TruSeq Stranded Total RNA kit (Illumina, Inc.) with ribosomal RNA removed using the Ribo-Zero Plant (leaf) kit (Illumina, Inc.). Prepared libraries were multiplexed and sequenced on a single lane of a HiSeq2000 DNA sequencer (Illumina, Inc.) to yield 100 bp paired-end reads.

Adapter clipping and quality trimming of reads was carried out using FastQC (v0.11.9; RRID:SCR_014583) [72] and fastq-mcf [73] with default parameters except for a minimum read length of 36 . Reads were mapped to tRNA and rRNA references sequences downloaded from the rfam database (v12.0; RRID:SCR_007891) [74] and $V$. Vinifera tRNA sequences downloaded from GtRNAdb (v18.1; RRID:SCR_006939) [75] using HISAT2 (v2.2.1; RRID:SCR_015530) [76]. Reads that mapped to tRNA and rRNA sequences were excluded. Reads were then mapped to the $V$. vinifera PN40024 12X reference genome [63] using HISAT2 with the parameter ' $\mathrm{k}$ 100' to allow multi-mapping. Gene and TE transcripts were counted simultaneously with TEtranscripts (v2.2.1) [77], using the V2.1 gene and TE annotation tracks described above.

Read counts for two genes demonstrating evidence of genome over-assembly (VIT_213s0019g0263 and VIT_ 207s0031g03000) were removed from raw count tables prior differential expression (DE) analysis using DEseq2 (v1.28.1; RRID:SCR_015687) [78]. Genes showing DE (Benjamini-Hochberg adjusted $p$-value $<0.05$ ) and a $2 \mathrm{x}$ change between tissues were considered to be differentially expressed genes (DEGs). Gene ontology (GO) terms associated with DEGs were retrieved from the CRIBI database (http:/genomes.cribi.unipd.it/DATA/V2/annotation/ bl2go.annot.txt), and enrichment analysis was performed 
using the fatiGO algorithm of the Babelomics software package (v5; RRID:SCR_002969) [79]. GO terms with FDR-adjusted $p$-values $<0.01$ were then passed to REViGO (RRID:SCR_005825) for grouping [80].

To compare the expression of TEs with co-located genes, only reads uniquely mapping to the genome were used. Reads mapping to exons and TEs (exons excluded) were counted separately using featureCounts (v2.0.0; RRID:SCR_012919) [81]. Count tables for both feature types were concatenated and analysed for DE using DEseq2 per Macchietto et al. [82].

All libraries were also mapped to the $V$. Vinifera cv. 'Chardonnay' reference genome [83] Although mapping reads to the Chardonnay reference resulted in a higher proportion of mapped reads, the majority of these were not properly paired and would therefore not be included in the downstream analysis pipeline (Suppl. Table S5). Instead, alignments to the more commonly used PN40024 reference genome, which showed high mapping rates as well as high proportions of properly paired reads, were used for further analysis.

\section{Small RNA analysis}

Small RNA (<200 nt) was purified from $50 \mathrm{mg}$ each of embryogenic cell cultures and young leaf tissue described above, using the Plant microRNA Purification Kit (Norgen BioTek Corp.) according to manufacturer's instructions. RNA samples were sent to New Zealand Genomics Ltd. (Auckland, New Zealand), where a 18-35 nt fraction of the each RNA sample was isolated by polyacrylamide gel electrophoresis and sequencing libraries were prepared using the TruSeq Small RNA library Preparation kit (Illumina, Inc.). The two libraries were sequenced on a single flow cell on a MiSeq DNA sequencer (Illumina, Inc.) using a 50 bp single-end sequencing protocol.

Adapter trimming and size filtering of sequence reads was performed in the UEA small RNA Workbench (v4.5; RRID:SCR_020947) [84]. Reads that mapped to $V$. vinifera tRNA and rRNA sequences, as described above, were removed using PatMaN (v1.2.2; RRID:SCR_011821) [85]. Identification of miRNA and their removal has been described elsewhere [42]. After removal of miRNAs, small RNAs were mapped to the reference genome using ShortStack (v3.8.5; RRID:SCR_010834) [86], which selects unique mapping sites for multi-mapping reads based on the location of unique-mapping reads. ShortStack was also used to perform siRNA cluster discovery and assign DicerCalls, based on the predominant fragment size for each cluster. Enrichment of 20 to $24 \mathrm{nt}$ cluster sizes across three genomic feature types: genes, promoters (defined as regions $2 \mathrm{~kb}$ upstream of genes) and TEs, was assessed using Genomic Association Tester (v1.3.6; RRID:SCR_020949) [87].

\section{Abbreviations}

DE: Differentially expressed; DRTS: Developmental relaxation of TE silencing; dsRNA: Double-stranded RNA; EC: Embryogenic callus; FDR: False discovery rate; GAT: Genomic Association Tester; GO: Gene ontology; hetsiRNA: Heterochromatic small interfering RNA; LINEs: Long interspersed nuclear elements; miRNA: micro RNA; MULE: Mutator-like element; PTGS: Post-transcriptional gene silencing; RdDM: RNA-directed DNA methylation; RNAi: RNA interference; RPM: Reads per million; siRNA: Small interfering RNA; sRNA: Small RNA; TE: Transposable element;

TGS: Transcriptional gene silencing

\section{Supplementary Information}

The online version contains supplementary material available at https://doi. org/10.1186/s12864-021-07973-9.

\section{Additional file 1: Figure S1. TE abundance in the Vitis vinifera} genome. A: Counts of annotated TEs per superfamily. B: Total coverage of the reference genome for each TE superfamily (total coverage by exons is plotted for comparison).

Additional file 2: Figure S2. Gene Ontology terms enriched among DE genes highly expressed in leaf tissue relative to EC. Enriched terms were grouped by similarity using REVIGO.

Additional file 3: Table S1. Sequencing libraries used in this study. Additional file 4: Table S2. Genes differentially expressed between EC and leaf.

Additional file 5: Table S3. TE families differentially expressed between EC and leaf.

Additional file 6: Table S4. Sequence reads remaining after successive filtering steps for small RNA libraries.

Additional file 7: Table S5. Mapping statistics for read libraries.

\section{Acknowledgements}

The authors thank Susan Thompson (Plant and Food Research New Zealand Ltd.) for bioinformatics advice.

\section{Authors' contributions}

$\mathrm{DL}$ and $\mathrm{CW}$ conceived the project and designed the experiments. DL analysed the data and prepared the manuscript. DL, RB and CW interpreted the data. All authors read and approved the final manuscript.

\section{Funding}

This work was supported by the Bragato Research Institute, Plant and Food Research New Zealand Ltd., Lincoln University and New Zealand Winegrowers. The funding bodies played no role in the design of the study and collection, analysis, and interpretation of data and in writing the manuscript.

\section{Availability of data and materials}

The data generated in this study have been deposited in Gene Expression Omnibus under the accession number GSE164586, except for the TE annotation track, which is available at DOl: https://doi.org/10.6084/m9. figshare.14709816. The $V$. vinifera PN40024 12X reference genome used is available under the GenBank assembly accession number GCA_000003745.2. and the $V$. vinifera chloroplast sequence used is available under the GenBank accession number NC_007957.1.

\section{Declarations}

Ethics approval and consent to participate

Not applicable.

Consent for publication

Not applicable.

Competing interests

The authors declare that they have no competing interests. 


\section{Author details}

${ }^{1}$ Bragato Research Institute, Blenheim, Marlborough, New Zealand. ${ }^{2}$ Plant and Food Research Ltd, Lincoln, Canterbury, New Zealand. ${ }^{3}$ Department Wine, Food and Molecular Biosciences, Lincoln University, Canterbury, New Zealand.

Received: 17 February 2021 Accepted: 3 September 2021 Published online: 20 September 2021

\section{References}

1. Ferrer MM, Good SV. Self-sterility in flowering plants: preventing selffertilization increases family diversification rates. Ann Bot. 2012;110:535-53.

2. Fujii S, Kubo K, Takayama S. Non-self- and self-recognition models in plant self-incompatibility. Nat Plants. 2016;2:16130.

3. McGovern P, Jalabadze M, Batiuk S, Callahan MP, Smith KE, Hall GR, et al. Early Neolithic wine of Georgia in the South Caucasus. Proc Natl Acad Sci USA. 2017;114:E10309-18.

4. Bowers J, Boursiquot J-MM, This P, Chu K, Johansson H, Meredith C. Historical genetics: the parentage of chardonnay, gamay, and other wine grapes of Northeastern France. Science. 1999;285:1562-5.

5. McCutcheon E, Bruwer J, Li E. Region of origin and its importance among choice factors in the wine-buying decision making of consumers. Int J Wine Bus Res. 2009;21:212-34.

6. Vivier MA, Pretorius IS. Genetically tailored grapevines for the wine industry. Trends Biotechnol. 2002;20:472-8.

7. This P, Lacombe T, Thomas MR. Historical origins and genetic diversity of wine grapes. Trends Genet. 2006;22:511-9.

8. Carrier G, Le Cunff L, Dereeper A, Legrand D, Sabot F, Bouchez O, et al. Transposable elements are a major cause of somatic polymorphism in Vitis vinifera L. PLoS One. 2012;7:e32973.

9. Kunze R, Saedler H, Lönnig WE, Lonnig WE. Plant transposable elements. Adv Bot Res. 1997;27:331-470.

10. Zhou Y, Minio A, Massonnet M, Solares E, LV Y, Beridze T, et al. The population genetics of structural variants in grapevine domestication. Nat Plants. 2019:5:965-79.

11. Benjak A, Forneck A, Casacuberta JM. Genome-Wide Analysis of the "'Cutand-Paste"' Transposons of Grapevine. PLoS One. 2008;3:e3107.

12. Borges F, Martienssen RA. The expanding world of small RNAs in plants. Nat Rev Mol Cell Biol. 2015;16:727-41.

13. Fultz D, Choudury SG, Slotkin RK. Silencing of active transposable elements in plants. Curr Opin Plant Biol. 2015:27:67-76.

14. Law JA, Jacobsen SE. Establishing, maintaining and modifying DNA methylation patterns in plants and animals. Nat Rev Genet. 2010;11:204-20.

15. Wang N, Xiang $Y$, Fang L, Wang $Y$, Xin H, Li S. Patterns of gene duplication and their contribution to expansion of gene families in Grapevine. Plant Mol Biol Report. 2013;31:852-61.

16. Naito K, Zhang F, Tsukiyama T, Saito H, Hancock CN, Richardson AO, et al. Unexpected consequences of a sudden and massive transposon amplification on rice gene expression. Nature. 2009;461:1130-4.

17. Daxinger $L$, Kanno $T$, Bucher $E$, Van Der Winden J, Naumann U, Matzke AJM, et al. A stepwise pathway for biogenesis of 24-nt secondary siRNAs and spreading of DNA methylation. EMBO J. 2009;28:48-57.

18. Slotkin RK, Martienssen R. Transposable elements and the epigenetic regulation of the genome. Nat Rev Genet. 2007:8:272-85.

19. Lanciano S, Mirouze M. Transposable elements: all mobile, all different, some stress responsive, some adaptive? Curr Opin Genet Dev. 2018;49:10614.

20. Dubin MJ, Mittelsten Scheid O, Becker C. Transposons: a blessing curse. Curr Opin Plant Biol. 2018;42:23-9.

21. Paszkowski J. Controlled activation of retrotransposition for plant breeding Curr Opin Biotechnol. 2015;32:200-6.

22. Guan Y, Li SG, Fan XF, Su ZH. Application of somatic embryogenesis in woody plants. Front Plant Sci. 2016;7:1-12.

23. Li ZT, Dhekney S, Dutt M, Aman M, Van, Tattersall J, Kelley KT, et al. Optimizing Agrobacterium-Mediated Transformation of Grapevine. Vitr Cell Dev Biol Plant. 2006;42:220-7

24. Ribas AF, Dechamp E, Champion A, Bertrand B, Combes M-C, Verdeil J-L, et al. Agrobacterium-mediated genetic transformation of Coffea arabica (L.) is greatly enhanced by using established embryogenic callus cultures. BMC Plant Biol. 2011;11:92.
25. Wang X, Tu M, Wang D, Liu J, Li Y, Li Z, et al. CRISPR/Cas9-mediated efficient targeted mutagenesis in grape in the first generation. Plant Biotechnol J. 2018;16:844-55

26. Grandbastien M. Activation of plant retrotransposons under stress conditions. Trends Plant Sci. 1998;3:181-7.

27. Kaeppler SM, Kaeppler HF, Rhee Y. Epigenetic aspects of somaclonal variation in plants. Plant Mol Biol. 2000;43:179-88.

28. Schellenbaum P, Mohler V, Wenzel G, Walter B. Variation in DNA methylation patterns of grapevine somaclones (Vitis vinifera L.). BMC Plant Biol. 2008;8:78.

29. Baránek M, Křižan B, Ondrušíková E, Pidra M. DNA-methylation changes in grapevine somaclones following in vitro culture and thermotherapy. Plant Cell Tissue Organ Cult. 2010;101:11-22.

30. Han Z, Crisp PA, Stelpflug S, Kaeppler SM, Li Q, Springer NM. Heritable epigenomic changes to the maize methylome resulting from tissue culture. Genetics. 2018;209:983-95

31. Ong-Abdullah M, Ordway JM, Jiang N, Ooi S-E, Kok S, Sarpan N, et al. Loss of Karma transposon methylation underlies the mantled somaclonal variant of oil palm. Nature. 2015:525:533-7.

32. Johannes F, Porcher E, Teixeira FK, Saliba-Colombani V, Simon M, Agier N, et al. Assessing the Impact of Transgenerational Epigenetic Variation on Complex Traits. PLoS Genet. 2009;5:e1000530.

33. Ocaña J, Walter B, Schellenbaum P. Stable MSAP markers for the distinction of vitis vinifera cv pinot noir clones. Mol Biotechnol. 2013;55:236-48.

34. Xie H, Konate M, Sai N, Tesfamicael KG, Cavagnaro T, Gilliham M, et al. Global DNA Methylation Patterns Can Play a Role in Defining Terroir in Grapevine (Vitis vinifera cv. Shiraz). Front Plant Sci. 2017;8:1-16.

35. Varela A, Ibañez VN, Alonso R, Zavallo D, Asurmendi S, Gomez Talquenca S, et al. Vineyard environments influence Malbec grapevine phenotypic traits and DNA methylation patterns in a clone-dependent way. Plant Cell Rep. 2021:40:111-25

36. Thiebaut F, Hemerly AS, Ferreira PCG. A role for epigenetic regulation in the adaptation and stress responses of non-model plants. Front Plant Sci. 2019: 10;1-7.

37. Hsu F-M, Gohain M, Allishe A, Huang Y-J, Liao J-L, Kuang L-Y, et al. Dynamics of the Methylome and Transcriptome during the Regeneration of Rice. Epigenomes. 2018;2:1-19.

38. Tanurdzic M, Vaughn MW, Jiang H, Lee T-J, Slotkin RK, Sosinski B, et al. Epigenomic Consequences of Immortalized Plant Cell Suspension Culture. PLoS Biol. 2008;6:e302.

39. Stroud $H$, Ding B, Simon SA, Feng S, Bellizzi M, Pellegrini $M$, et al. Plants regenerated from tissue culture contain stable epigenome changes in rice. Elife. 2013;2013:1-14

40. Chapman B, Bellgard M. Plant proteogenomics: improvements to the grapevine genome annotation. Proteomics. 2017;17:1-9.

41. Li Y, Zhang S, Dong R, Wang L, Yao J, Van Nocker S, et al. The grapevine homeobox gene $V_{V} H B 58$ influences seed and fruit development through multiple hormonal signaling pathways. BMC Plant Biol. 2019:19:1-18.

42. Lizamore D, Winefield C. A comparative survey of small RNA and their targets in grapevine embryogenic callus cultures and young leaves. Acta Hortic. 2017;1188:329-36.

43. Peschke VM, Phillips RL, Gengenbach BG. Discovery of transposable element activity among progeny of tissue culture-derived maize plants. Science. 1987;238:804-7

44. Hirochika H, Sugimoto K, Otsuki Y, Tsugawa H, Kanda M. Retrotransposons of rice involved in mutations induced by tissue culture. Proc Natl Acad Sci. 1996;93:7783-8.

45. Rival A, Ilbert P, Labeyrie A, Torres E, Doulbeau S, Personne A, et al. Variations in genomic DNA methylation during the long-term in vitro proliferation of oil palm embryogenic suspension cultures. Plant Cell Rep. 2013:32:359-68.

46. Grandbastien MA. LTR retrotransposons, handy hitchhikers of plant regulation and stress response. Biochim Biophys Acta - Gene Regul Mech. 2015;1849:403-16

47. Azizi P, Hanafi MM, Sahebi M, Harikrishna JA, Taheri S, Yassoralipour A, et al. Epigenetic changes and their relationship to somaclonal variation: a need to monitor the micropropagation of plantation crops. Funct Plant Biol. 2020; 47:508-23.

48. Park D, Choi I-Y, Kim N-S. Detection of mPing mobilization in transgenic rice plants. Genes Genomics. 2020;42:47-54. 
49. Tang X, Liu G, Zhou J, Ren Q, You Q, Tian L, et al. A large-scale wholegenome sequencing analysis reveals highly specific genome editing by both Cas9 and Cpf1 (Cas12a) nucleases in rice. Genome Biol. 2018;19:1-13.

50. Krishna $H$, Alizadeh $M$, Singh $D$, Singh $U$, Chauhan N, Eftekhari $M$, et al Somaclonal variations and their applications in horticultural crops improvement. 3 Biotech. 2016;6:1-18.

51. Miyao A, Tanaka K, Murata K, Sawaki H, Takeda S, Abe K, et al. Target site specificity of the Tos 17 retrotransposon shows a preference for insertion within genes and against insertion in retrotransposon-rich regions of the genome. Plant Cell. 2003;15:1771-80.

52. Małolepszy A, Mun T, Sandal N, Gupta V, Dubin M, Urbański D, et al. The LORE1 insertion mutant resource. Plant J. 2016;88:306-17.

53. McClintock B. The origin and behavior of mutable loci in maize. Proc Natl Acad Sci. 1950;36:344-55.

54. Zakrzewski F, Schmidt M, Van Lijsebettens M, Schmidt T. DNA methylation of retrotransposons, DNA transposons and genes in sugar beet (Beta vulgaris L.). Plant J. 2017:90:1156-75.

55. Niederhuth CE, Bewick AJ, Ji L, Alabady MS, Kim K, Do, Li Q, et al. Widespread natural variation of DNA methylation within angiosperms. Genome Biol. 2016;17:1-19.

56. Bartels A, Han Q, Nair P, Stacey L, Gaynier H, Mosley M, et al. Dynamic DNA Methylation in Plant Growth and Development. Int J Mol Sci. 2018;19:2144.

57. An YQC, Goettel W, Han Q, Bartels A, Liu Z, Xiao W. Dynamic Changes of Genome-Wide DNA Methylation during Soybean Seed Development. Sci Rep. 2017;7:1-14.

58. Bouyer D, Kramdi A, Kassam M, Heese M, Schnittger A, Roudier F, et al. DNA methylation dynamics during early plant life. Genome Biol. 2017;18:1-12.

59. Martínez G, Slotkin RK. Developmental relaxation of transposable element silencing in plants: functional or byproduct? Curr Opin Plant Biol. 2012;15: 496-502.

60. Li H, Freeling M, Lisch D. Epigenetic reprogramming during vegetative phase change in maize. Proc Natl Acad Sci U S A. 2010;107:22184-9.

61. Slotkin RK, Vaughn M, Borges F, Tanurdžić M, Becker JDJD, Feijó JA, et al. Epigenetic reprogramming and small RNA silencing of transposable elements in pollen. Cell. 2009;136:461-72.

62. Hsieh T-F, Ibarra CA, Silva P, Zemach A, Eshed-Williams L, Fischer RL, et al. Genome-wide demethylation of Arabidopsis endosperm. Science. 2009;324: $1451-4$

63. Adam-Blondon AF, Jaillon O, Vezzulli S, Zharkikh A, Troggio M, Velasco R. Genome sequence initiatives. In: Adam-Blondon AF, Martinez-Zapater JM, Kole C, editors. Genetics, Genomics, and Breeding of Grapes. Boca Raton: CRC Press; 2011. p. 211-34

64. Smit A, Hubley R, Green P. RepeatMasker Open-4.0. 2013. http://www.repea tmasker.org

65. Jurka J, Kapitonov W, Pavlicek A, Klonowski P, Kohany O, Walichiewicz J. Repbase Update, a database of eukaryotic repetitive elements. Cytogenet Genome Res. 2005;110:462-7.

66. Vitulo N, Forcato C, Carpinelli EC, Telatin A, Campagna D, D'Angelo M, et al. A deep survey of alternative splicing in grape reveals changes in the splicing machinery related to tissue, stress condition and genotype. BMC Plant Biol. 2014;14:99.

67. Quinlan AR, Hall IM. BEDTools:. A flexible suite of utilities for comparing genomic features. Bioinformatics. 2010;26:841-2.

68. Perrin M, Gertz C, Masson JEE. High efficiency initiation of regenerable embryogenic callus from anther filaments of 19-grapevine genotypes grown worldwide. Plant Sci. 2004;167:1343-9.

69. Torregrosa L. A simple and efficient method to obtain stable embryogenic cultures from anthers of Vitis vinifera L. Vitis. 1998;37:91-2.

70. Guo W, Fiziev P, Yan W, Cokus S, Sun X, Zhang MQ, et al. BS-Seeker2: A versatile aligning pipeline for bisulfite sequencing data. BMC Genom. 2013; 14:302-7.

71. Guo W, Zhu P, Pellegrini M, Zhang MQ, Wang X, Ni Z. CGmapTools improves the precision of heterozygous SNV calls and supports allelespecific methylation detection and visualization in bisulfite-sequencing data. Bioinformatics. 2018:34:381-7.

72. Andrews S. FASTQC: A quality control tool for high throughput sequence data. http://www.bioinformatics.babraham.ac.uk/projects/fastqc. 2010.

73. Aronesty E. Comparison of sequencing utility programs. Open Bioinform J. 2013;7:1-8.
74. Nawrocki EP, Burge SW, Bateman A, Daub J, Eberhardt RY, Eddy SR, et al. Rfam 12.0: Updates to the RNA families database. Nucleic Acids Res. 2015; 43:D130-7.

75. Chan PP, Lowe TM. GtRNAdb 2.0: An expanded database of transfer RNA genes identified in complete and draft genomes. Nucleic Acids Res. 2016; 44:D184-9.

76. Kim D, Langmead B, Salzberg SL. HISAT: a fast spliced aligner with low memory requirements. Nat Methods. 2015;12:357-60.

77. Jin $Y$, Tam OH, Paniagua E, Hammell M. TEtranscripts. A package for including transposable elements in differential expression analysis of RNAseq datasets. Bioinformatics. 2015:31:3593-9.

78. Love MI, Huber W, Anders S. Moderated estimation of fold change and dispersion for RNA-seq data with DESeq2. Genome Biol. 2014;15:550.

79. Al-Shahrour F, Díaz-Uriarte R, Dopazo J. FatiGO: A web tool for finding significant associations of Gene Ontology terms with groups of genes. Bioinformatics. 2004;20:578-80.

80. Supek F, Bošnjak M, Škunca N, Šmuc T. REVIGO Summarizes and Visualizes Long Lists of Gene Ontology Terms. PLoS One. 2011;6:e21800.

81. Liao Y, Smyth GK, Shi W. FeatureCounts. An efficient general purpose program for assigning sequence reads to genomic features. Bioinformatics. 2014;30:923-30.

82. Macchietto MG, Langlois RA, Shen SS. Virus-induced transposable element expression up-regulation in human and mouse host cells. Life Sci Alliance. 2020;3:e201900536.

83. Roach MJ, Johnson DL, Bohlmann J, van Vuuren HJJ, Jones SJM, Pretorius IS, et al. Population sequencing reveals clonal diversity and ancestral inbreeding in the grapevine cultivar Chardonnay. PLOS Genet. 2018;14: e1007807.

84. Stocks MB, Moxon S, Mapleson D, Woolfenden HC, Mohorianu I, Folkes L, et al. The UEA sRNA workbench: A suite of tools for analysing and visualizing next generation sequencing microRNA and small RNA datasets. Bioinformatics. 2012;28:2059-61.

85. Prüfer K, Stenzel U, Dannemann M, Green RE, Lachmann M, Kelso J. PatMaN. Rapid alignment of short sequences to large databases. Bioinformatics. 2008;24:1530-1.

86. Axtell MJ. ShortStack: comprehensive annotation and quantification of small RNA genes. RNA. 2013;19:740-51.

87. Heger A, Webber C, Goodson M, Ponting CP, Lunter G. GAT: A simulation framework for testing the association of genomic intervals. Bioinformatics. 2013;29:2046-8

\section{Publisher's Note}

Springer Nature remains neutral with regard to jurisdictional claims in published maps and institutional affiliations.

\section{Ready to submit your research? Choose BMC and benefit from:}

- fast, convenient online submission

- thorough peer review by experienced researchers in your field

- rapid publication on acceptance

- support for research data, including large and complex data types

- gold Open Access which fosters wider collaboration and increased citations

- maximum visibility for your research: over $100 \mathrm{M}$ website views per year

At $\mathrm{BMC}$, research is always in progress.

Learn more biomedcentral.com/submissions 